\title{
Research on Training Mode Reform of Innovative Talents for Software Engineering Major
}

\author{
Yuqiang Yang ${ }^{1, a}$, Ying Zhao ${ }^{2, b}$, Hang Wang ${ }^{3, c}$ \\ ${ }^{1}$ College of Information Science and Technology, Bohai University, Jinzhou, 121013, China \\ ${ }^{2}$ Computer Center, Liaoning University of Technology, Jinzhou, 121013, China \\ ${ }^{3}$ College of Engineering, Bohai University, Jinzhou, 121013, China \\ ayyq8369@163.com, 'Igjsjzy8@163.com, 'bhdxwanghang@163.com
}

Keywords: software engineering major; innovative talents; training mode; teaching reform

\begin{abstract}
The current cultivation of higher education applied talents, break away from the real social needs, despise cultivation of engineering practice ability, and with behind teaching methods and teaching means. This paper aims at the problems of software engineering major training, in order to meet the needs of the innovative talents of software enterprises, has formulated practical and feasible reform plan to improve the teaching quality of software engineering and promote the development of software industry in China. The main contents of the reform include: innovative top-level design, leading personnel training; update training programs, strengthen the ability to enhance; use of action-oriented teaching methods to optimize the classroom teaching process; to strengthen the construction of teachers to meet the needs of reform; industry needs, Educate people; form a reform leading group, improve the management mechanism.
\end{abstract}

\section{Introduction}

Software engineering is "software development, operation, maintenance and retreat system approach." Software engineering includes three elements: First, methods and techniques. Provide general principles, work frameworks, development strategies and practical techniques for software development. Including: lifecycle models, top-down methods, structured development methods, object-oriented development methods, requirements management and testing techniques. Second, tools and environment. Automated or semi-automated software support tools and environments for software engineering methods is important for improving software development productivity, ensuring software quality, software testing and integration, ease to maintenance, and improve visibility and control the process effect of software development. Third, management and standard. Software engineering methods and tools combined to ensure the reasonable and timely software development. Software engineering management mainly includes project, configuration, document, quality, cost, staff, schedule and so on. Software engineering standards are common guidelines for software development processes and software products, including basic standard, product standard, methods, technical standards, management and organization standard.

Software Engineering major is a new major in Ministry of Education in 2002. With the continuous expansion of computer applications and the continuous development of China's economic construction, software engineering major will become a new popular major. Software engineering major is based on computer science and technology subjects, emphasizing the engineering quality of software development, let students master the computer science and technology knowledge and skills on the basis of mastery in software demand analysis, software design, software testing, software maintenance, software project management and other necessary basic knowledge, basic methods and basic skills, highlighting the students' professional knowledge and professional skills training, training senior specialized talents can be engaged in software development, testing, maintenance and software project management.

At present, China's software talent training is mainly faced with two problems: first, lack of software talents, the contradiction between supply and demand, talent flow is too frequent, seriously affected the formation of innovative team and innovative technology product development. Second, 
knowledge and ability structure is unreasonable. Software talents training emphasis on academic, but industrial development and business demand need practical engineering ability talents. At present, there are a large number of continuing education institutions in society, which are specially designed for enterprises to cultivate talents with strong engineering practice ability, familiar with software development model and have solid theoretical basis. The vast majority of these institutions are derived from college graduates. Students graduate from institution of higher learning, but also need to have stable teachers and fixed experimental base of social institutions "subculture", in order to be recognized by the society. This shows that there are problems in the mode of talents training in institution of higher learning, the cultivation of applied talents is out of the reality of social needs, and the cultivation of engineering practice ability is not deserved, the teaching content has not kept pace with social development, and teaching methods and teaching means are backward. Therefore, we must carry out the training mode reform of talents, based on social needs, cultivate innovative talents, improve the quality of software engineering teaching and promote the development of China's software industry services.

\section{Talent Characteristics}

Creativity, is the innovation ability that is produced under the control of innovation consciousness, and the innovative talents are the talented people who are very prominent in innovation consciousness and innovation ability. To sum up, innovative talents generally have the following five basic characteristics:

(1) Encourage to explore the spirit of innovation. Innovative talents have good dedication and enterprising consciousness, strong sense of enterprise and historical sense of responsibility. This is the intrinsic driving force of innovation activities, is the potential power, but also the fundamental guarantee of continuous innovation. Innovative talents have realistic attitude and strict thinking logic, so as to ensure the accurate analysis, judgment and grasp the objective laws of things, and innovation and practice with spirit of scientific .

(2) Acute insight. Innovative talent performance exploratory in learning, performance good at thinking in action, emphasize "expected" in action, that is, before action have more careful design, which is the development of things with acute insight into performance. Thinking is also flexible, good at adjusting the way of thinking and mode of action things which is based on the development things, then take the most effective action strategy.

(3) Consciousness and ability of self-study. Learn to learn become the basic quality of life in the 21st century, innovative talents must have the consciousness and ability to self-study. The accelerated speed of information update make the learning stage and the division of the stage into history, learning become a life through a person, learning will be more important than ever before. Adapting to the needs of social development of innovative talents, must be able to experience the problems encountered, and take the initiative to learn.

(4) Perseverance will. Innovative talent insight, make it has a strong sense of innovation and high achievement desire, which has become a strong desire to action. Achievement of desire also provokes the courage and danger of challenging the difficulties, therefore not afraid of frustration and difficulties, and often regard setbacks and difficulties as a test of the will and suffering, overcome the difficulties as pleasure, and face failure to be stronger.

(5) Rich innovative knowledge. Innovation is the development of existed knowledge, the knowledge structure of innovative talents is both breadth and depth; both deep and solid basic knowledge, understand the adjacent subjects and the necessary crosswise subject knowledge, and proficient in professional knowledge, engaged in the latest professional achievements and development trends. This complete knowledge structure helps to enhance the comprehensive thinking ability and innovation ability. 


\section{Ability Structure}

The ability structure of innovative talents for software engineering major is mainly composed of the following six factors:

(1) Demand analysis. Demand analysis is an important work of software life cycle and it is a decisive work. Only through needs analysis can let the software functions and performance of the overall concept describe as specific software requirements specification, thus establish the foundation of software development. Demand analysis has decisive, directional and strategic function.

(2) Software design. Software design is from the software requirements specification, according to the needs of analysis stage to determine the function, design the overall structure of the software system, divide functional modules, determine the implementation algorithm of each module, and format specific software design. Software design includes structural design, data design, interface design and process design.

(3) Software implementation. Software implementation is based on the results of software design, write program modules which is correct, easy to understand and maintain, and these modules for debugging and unit testing. The main work of software implementation is to write computer programs, and usually uses structured programming methods and object-oriented programming methods.

(4) Software testing. Software testing is the process for executing program in order to find error. Software testing is not only an integral part of the software development stage, but also plays a very important role in the entire software engineering process. Software testing is the key link of software quality assurance, which directly affects the quality evaluation of software.

(5) Software maintenance. Software maintenance is after using the software delivery, in order to ensure it safe and operate stably to modify the process. Improve software lifecycle by modifying software defects, improving software performance or other attributes, letting software products adapt to new environment. Software maintenance is a time-consuming and energy-intensive job.

(6) Software project management. Software project management object is software engineering project, and the referred scope cover the entire software engineering process to make the software project successful completion and in accordance with the scheduled cost, progress, quality, and analysis and manage the staff, products, process, projects and so on.

\section{Reform Program}

In view of existing problem in the training of software engineering major talents, with reference to the characteristics of innovative talents and the ability structure of innovative talents of software engineering major, combined with my years of teaching and research experience, the reform plan is as follows:

(1) Innovation top-level design, lead talent training. Top-level design is the use of system theory, from the global perspective, at a task or at all aspects of the project, at all levels, elements overall planning to focus on effective resources, efficient and fast to achieve the goal. The top-level design emphasizes the interrelationships between the internal elements of the design object, the core concepts and top-level goals, matching the organic joint. The basic requirements of the top-level design are concise and clear, and the design results are practicable. The core of innovative talents for software engineering major training model can be summarized as "seize a main line, complete two combination, achieve three joint, consolidate four construction" and "1234 talent training project." "Seize a main line" is in the process of talent training has always been around "improve students practice ability," the main line to start. "Complete two combination" is the students during study period, achieve self-study and practice training combined, school learning and enterprise learning combined. "Achieve three joint" is to achieve the joint of professional education and vocational education, teaching content and professional needs, teaching process and production 
process. "Consolidate four construction" refers to the teaching staff construction, curriculum construction, teaching materials construction and practice base construction.

(2) Update training program, strengthen ability to enhancement. Innovative talents are not only the all-round development talents, the full development talents, but also on this basis make greater contributions to the social material civilization and spiritual civilization talents. Therefore, we must proceed from the reality of the university, take practical training programs, and effectively promote the cultivation of innovative talents. Innovative training programs will cultivate innovative talents, innovative training program has always been oriented to subject development and industry demand, establish scientific curriculum system, constantly optimize the teaching methods and evaluation methods, the curriculum content and social needs need to adapt to each other, in the new training program, the actual practice part has the proportion of more than $45 \%$, through the teaching process to strengthen the students basic skills training, implement the project case-style teaching methods reform, multiple evaluation methods to reform, build an open practice teaching system, the innovative spirit and practical ability of students improve significantly.

(3) Use action-oriented teaching method, optimize class teaching process. Action-oriented teaching method is in accordance with the professional work process to determine the learning area, set learning situation, make professional activities as guide, tasks as carrier, students through the hands and brain to use, inquiry and discovery learning to improve learning interest, cultivate innovative thinking, format key ability to competency-based teaching method. The establishment of modular and project-based curriculum system, students through the module courses, master a certain degree of vocational skills, which is the necessary conditions for the formation of relevant technical practice. On this basis, design relatively complete work items, through comprehensive practical activities, and ultimately contributed to the action skills, practical thinking, attitudes, values and other elements of the innovative practical ability. The key link in the implementation of action-oriented teaching method is "design good project teaching, make good use of case teaching, solidly carry out scene teaching, make good use of simulation teaching, implement post teaching." Teachers in the teaching process play the role of the provider and guide to help students understand the project background and project requirements, as soon as possible management and guide the student practice in the selection of development methods and software development process necessarily.

(4) Strengthen construction of teachers, meet reform needs. Teachers are the professionals who perform their duties of education and teaching, and undertake the mission of teaching and educating people, cultivating the builders of socialism and successors, and improving the quality of the nation. Create innovative and practical ability of the faculty, is the core to improve the quality of personnel training. Based on the actual needs of the future development of high-quality talents, pay attention to the formation of all-round and multi-level pattern of talents, implement full-time teachers as the core, inside teachers and outside teachers combined together, full-time teachers and part-time teachers together, college teachers and enterprise teachers combined together, domestic teachers and foreign teachers together with diversified source of teachers to build a school-enterprise cooperation in talents training mechanism and teacher training mechanism. And strive to after several years, the formation of full-time and part-time combination, excellent quality, adequate number, teachers team with innovative spirit and practical ability, for innovative talents to establish solid foundation.

(5) Face sector demand, cooperation between universities and enterprises. In view of the current situation of higher education talents training system closed, student engineering practice ability is weak, student employment and other problems, domestic large-scale software development enterprises establish enterprise training practice base, the formation of "alternating school and industry" talent training method, effectively solute the contradiction between industry demand and school education. In the first year, students went to experience the practice for 1 month; students in the second year, production practice for 2months; students in the third year, practical training for six months; students in the fourth year, practice for 1 year. This way achieve the closely links between professional education and vocational education, zero distance between school learning and social 
needs, "learning, practice and employment" integration. Form the "demand for industry development, school-enterprise collaborative mechanism innovation, academic alternately strengthen practice" concept of talents training, leading software engineering major innovative talents training.

(6) Format reform leading group, improve management mechanism. In order to promote the construction of software engineering specialty and ensure the successful implementation reform measures of innovative talents training mode, we will form a leading group for reforming the training mode for software engineering major. The group is composed of adviser, leadership and member layers. Among them, the consultant level composed of school principal, dean of studies, teaching committee director and supervisory group staff, responsible for the overall guidance and major decision-making; leadership level including institute leader as the group leader, didactical vice president as vice director of the group, director of teaching department as secretary-general, are responsible for teaching reform organization; members are made up of the professional leaders, backbone teachers and part-time teachers and other components, are responsible for the specific formulation and implementation of reform measures. Reform leading group in accordance with the recommendations of the professional advisory committee to develop professional construction planning, talents training programs and professional teaching standards, as well as the detailed implementation of the program, and organize the implementation of the professional management of the construction mechanism, each semester submit work plans and work summary, each work is checked and assessed aperiodically.

\section{Conclusion}

"Innovation is the soul of national progress, innovation is an inexhaustible motive force for the prosperity of country." In today's world of national competition, talent competition is the ultimate embodiment. The key factor to determine the level of talent competitiveness is rely on the education of innovation consciousness and innovation ability. This paper aims at the problems of software engineering major training, in order to meet the needs of the innovative talents of software enterprises, this paper has formulated the feasible reform plan and created new model for the cultivation of innovative talents in institutions of higher learning.

\section{Acknowledgement}

This work is supported by undergraduate teaching reform project of Liaoning province (2016300).

\section{References}

[1] L. F. Liu, Y. Liu, "Project oriented teaching method of computer practical courses," Computer Education, vol. 13, no. 7, pp. 47-50, 2015.

[2] X. T. Yu, X. F. Li, "Research on the characteristics and cultivation of innovative talents," Road to success, vol. 18, no. 36, pp. 1-2, 2015.

[3] M. Sun, M. Tian, W. J. Kang, "Design project driven software engineering practice teaching reform," Computer Education, vol. 14, no. 3, pp. 156-159, 2016.

[4] G. Q. Wang, D. B. Ren, "Exploration and Practice on Teaching Reform of Soft Engineering," Computer Knowledge and Technology, vol. 12, no. 23, pp. 115-117, 2016.

[5] Y. H. Tian, L. M. Liu, Z. Q. Ma, et al., Li, "Research and exploration on the practice teaching reform of School of software engineering," Journal of Inner Mongolia Agricultural University (Social Science Edition), vol. 18, no. 3, pp. 99-103, 2016.

[6] L. She, Y. Y. Zeng, R. Y. Chen, "Discussion on the teaching reform of software engineering in the era of big data," Computer Education, vol. 14, no. 2, pp. 127-129, 2016. 